\title{
Own experience improving port implantation in laparoscopic adjustable gastric banding
}

\author{
Tomasz Szewczyk, Przemysław Janczak, Bogdan Modzelewski \\ Department of Gastroenterological, Oncological and General Surgery, Medical University of Lodz, Poland
}

Videosurgery and Other Miniinvasive Techniques 2012; 7 (2): 82-88

DOI: 10.5114/wiitm.2011.27130

\begin{abstract}
Introduction: Laparoscopic adjustable gastric banding (LAGB) is a method frequently used for treating obesity. It requires periodic band regulation associated with the need for port puncture. However, there is always a substantial risk of port rotation.

Aim: This publication presents a solution of the problem for a MiniMizer Extra band.

Material and methods: One thousand one hundred and twenty-four individuals were operated on for obesity in the Department of Gastroenterological, Oncological and General Surgery of the Medical University of Lodz between 2005 and 2009. In 637 patients LAGB was performed. These LAGB patients were divided into three groups. In group I (20 patients) MiniMizer Extra bands were placed without port stabilization. In the second group (292 patients) MiniMizer Extra band placement with port stabilization was commenced. In the third group (325 patients) bands of other manufacturers (AMI, Inamed, Midband, Obtech) were used without port stabilization. The port was implanted into the subcutaneous tissue in the left subcostal region, medial to the left working tool trocar position.

Results: Port rotation was observed on the very first band adjustment in $3(0.92 \%)$ and 11 (55\%) patients with a band other than MiniMizer Extra $(n=325)$ and the first 20 patients with a MiniMizer Extra band. A different technique of port stabilization was applied in a further 292 patients on MiniMizer Extra band placement and no port rotation was noted.

Conclusions: We believe that MiniMizer additional port stabilization is necessary for its frequent rotation. Simultaneously, application of our method is easy, does not prolong the procedure significantly and secures comfortable access to the port.
\end{abstract}

Key words: laparoscopic adjustable gastric banding, port, complication.

\section{Introduction}

Laparoscopic adjustable gastric banding (LAGB) is a popular method of surgical treatment for obesity, especially in Europe and Australia. Unlike other methods, it requires periodical band adjustments. To do this, port puncture is necessary, which sometimes turns out to be difficult, particularly when port rotation has occurred.

\section{Aim}

In this publication we present a method to deal with port rotation of the MiniMizer Extra adjustable band manufactured by Bariatric Solution (previously HospiMedical).

\section{Material and methods}

One thousand one hundred and twenty-four individuals were operated on for obesity in the Department of Gastroenterological, Oncological and General Surgery of the Medical University of Lodz between 2005 and 2009. In 637 patients LAGB was performed. Three hundred and twelve MiniMizer Extra bands (49\%) were placed, as well as 192 Obtech (30.1\%), 83 Midband (13\%), 41 AMI (6.4\%) and 9 Inamed (1.4\%) 
devices. From January 2007, MiniMizer Extra bands were applied (Table I).

There were 329 women (51.7\%) and 308 men (48.3\%) in this group. Mean body mass index (BMI) of the operated patients was $44.99 \mathrm{~kg} / \mathrm{m}^{2}$ (34.34$64.56 \mathrm{~kg} / \mathrm{m}^{2}$ ). Demographic data are shown in Table II.

Procedures were always performed by the same operating team using the 'pars flaccida' technique. The port was placed subcutaneously in the left epigastric region, medially to the entrance of the trocar through which the band was passed into the peritoneal cavity (Figure 1). A 6-8 cm canal was formed with a finger or surgical tool starting from the trocar entry medially. The canal began at $4 \mathrm{~cm}$ depth and ended $2 \mathrm{~cm}$ under the skin. The port was not stabilized with additional sutures. After 20 initial proce- dures with MiniMizer Extra bands (group I), the port stabilization technique was developed due to a significant port rotation rate during band adjustment. The technique consists of placement of 3 skin stitches at the projected port location. The sutures first run through the canal. After passing the sutures through the eyes of the port they are redirected through the canal to re-emerge above the skin. The port is accommodated through the canal in a correct position while tightening the sutures, and constantly controlling its location (Figure 2). Tying of the sutures ends this step of the procedure. The trocar wound was closed with interrupted sutures (Figure 3). Sutures were removed 7 days later. Prolene 2.0 on a large needle was used. This modified technique was applied in 292 patients (group II). Patients in whom bands other than Mini-

Table I. Bands applied

\begin{tabular}{|lcccccc|}
\hline & AMI & Inamed & Midband & MiniMizer Extra & Obtech & Total \\
\hline$n(\%)$ & $41(6.44)$ & $9(1.41)$ & $83(13.03)$ & $312(48.98)$ & $192(30.14)$ & $637(100)$ \\
\hline
\end{tabular}

Table II. Demografic data

\begin{tabular}{|lccccc|}
\hline & $n(\%)$ & Age [years] & Height $[\mathrm{m}]$ & Weight $[\mathrm{kg}]$ & BMI $\left[\mathrm{kg} / \mathrm{m}^{2}\right]$ \\
\hline Women & $329(51.65)$ & $42(23-65)$ & $1.64(1.48-1.80)$ & $112(79-181)$ & $43.31(34.87-60.97)$ \\
\hline Men & $308(48.35)$ & $48(22-65)$ & $1.78(1.65-2.00)$ & $149(105-215)$ & $46.8(34.34-64.56)$ \\
\hline Total & $637(100)$ & $45(22-65)$ & $1.71(1.48-2.00)$ & $130(79-215)$ & $44.99(34.34-64.56)$ \\
\hline
\end{tabular}

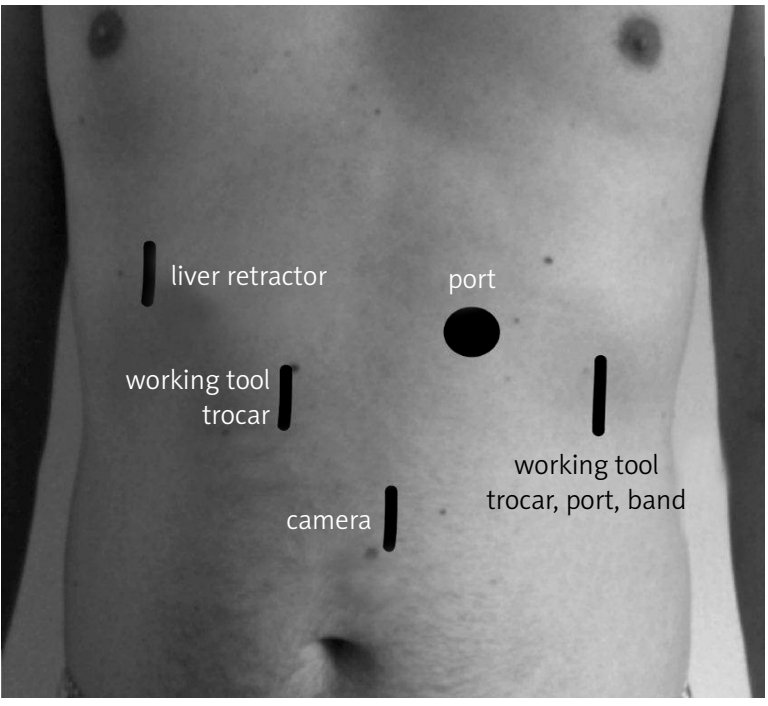

Figure 1. Trocar placement

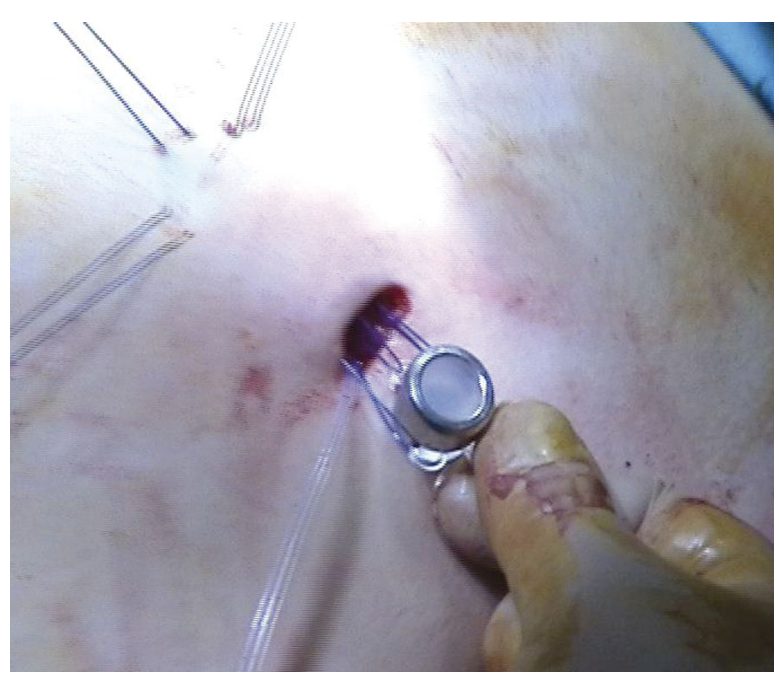

Figure 2. Placement of the port stabilizing sutures 


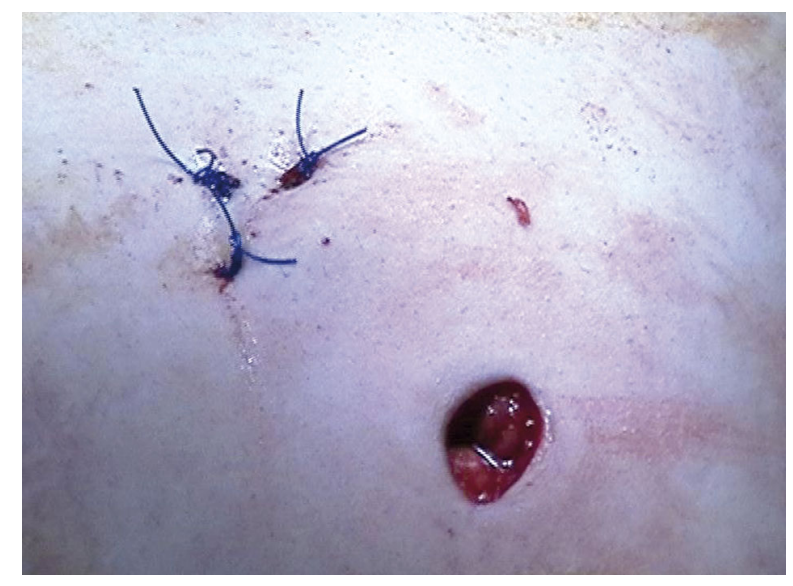

Figure 3. Trocar insertion area after port stabilization

Mizer Extra were used $(n=325)$ had ports positioned as in group I and were classified as group III (Table III).

The first band adjustment was done 4-6 weeks after the surgery. The port position was controlled with palpation and radiologically. Accessibility of the membrane for needle puncture was assessed. Subsequent regulations took place every 6 weeks during the first 6 months, then 3-monthly, and from the second year of follow-up every 6 months or whenever complications occurred.

Duration of surgery was noted as well as time needed for port stabilization, and port-associated complication rate - rotation, infection, connecting drain disjunction, leakage, injury.

Dimensions of each port were marked and an index (the ratio of its height to the diameter) was calculated (Table IV).

\section{Statistical analysis}

Results were analysed statistically with STATISTICA software. Wilcoxon-Mann-Whitney and $\chi^{2}$ tests were used to compare binary data. Value of $p<0.05$ was considered significant.

\section{Results}

Mean operation time in group I was 19 min (10-45 $\mathrm{min}$ ), in group II $24 \mathrm{~min}$ (13-45 min) and in group III $20 \mathrm{~min}$ (10-48 min). No statistically significant differences between the groups were found. In group I average port placement duration was $37.2 \mathrm{~s}$ (15-55 s), in group II $234 \mathrm{~s}$ (185-300 s), and in group III $43.2 \mathrm{~s}$ (20-60 s). There was a statistically significant difference between group II and the other groups (I vs. II, $p<0.001$, II vs. III, $p<0.05$, Table V).

In the first group rotation of the port was found in 11 patients (55\%) on the first Inamed adjustment. There were no rotations in group II and in group III rotation occurred in 3 patients (0.92\%). During further follow-up port dislocation was found in 2 pa-

Table III. Study groups

\begin{tabular}{|lcccc|}
\hline Group & $n(\%)$ & Height $[\mathrm{m}]$ & Weight $[\mathrm{kg}]$ & BMI $\left[\mathrm{kg} / \mathrm{m}^{2}\right]$ \\
\hline I & $20(3.14)$ & $1.67(1.5-1.83)$ & $131.3(99-180)$ & $46.82(35.79-65.32)$ \\
\hline II & $292(45.86)$ & $1.7(1.53-1.88)$ & $126.5(87-197)$ & $43.74(38.75-62.88)$ \\
\hline III & $325(51)$ & $1.69(1.48-2.00)$ & $130.18(79-215)$ & $45.15(34.34-64.56)$ \\
\hline
\end{tabular}

Table IV. Port height to diameter ratio in different bands

\begin{tabular}{|ll|}
\hline Band type & \\
\hline AMI & 0.46 \\
\hline Helioscope & 0.47 \\
\hline Inamed & 0.45 \\
\hline Midband & 0.48 \\
\hline MiniMizer & 0.82 \\
\hline Obtech & 0.37 \\
\hline
\end{tabular}

Table V. Duration of the procedure

\begin{tabular}{|lccc|}
\hline & Group I & Group II & Group III \\
\hline $\begin{array}{l}\text { Operation time } \\
\text { [min] }\end{array}$ & $\begin{array}{c}19 \\
(10-45)\end{array}$ & $\begin{array}{c}24 \\
(13-45)\end{array}$ & $\begin{array}{c}20 \\
(10-48)\end{array}$ \\
\hline Statistics & \multicolumn{2}{c}{ NS } & \multicolumn{2}{c|}{ NS } \\
\hline $\begin{array}{l}\text { Port insertion } \\
\text { duration [s] }\end{array}$ & $\begin{array}{c}37.2 \\
(20-55)\end{array}$ & $\begin{array}{c}234 \\
(185-300)\end{array}$ & $\begin{array}{c}43.2 \\
(20-60)\end{array}$ \\
\hline Value of $p$ & \multicolumn{2}{c}{$<0.001$} & $<0.05$ \\
\hline
\end{tabular}


tients (10\%) from group I, 3 patients (1.03\%) in group II and 3 patients (0.92\%) from group III 12 months after surgery. In patients with port rotation 6 weeks after the procedure (14 patients, $2.42 \%)$, in 6 cases $(1.03 \%)$ it was a rotation by $180^{\circ}$ making membrane puncture impossible. In these patients a surgical correction of the port position was done with the aforementioned technique. The procedure was done in an outpatient clinic under local anaesthesia. There were no rotations found in these patients during subsequent adjustments.

Patients in whom rotation was discovered 12 months after surgery at the same time had significant weight reduction of over $75 \%$ of excess weight loss. Loose skin was also present, allowing puncture of the port after taking hold of it and stabilization.

One patient from group III (0.3\%) needed port relocation due to her professional habits, interfered with by port position. The patient is a midwife, and during the delivery she puts the lower limb of those giving birth against the original port placement location. The port was repositioned to the hypogastric region with the standard technique. A mechanical injury to the port with separation of the connecting drain occurred in one patient from group II (0.34\%) 18 months after the procedure. The port was changed for a new one, which was stabilized as described above under local anaesthesia.

In 1 patient $(0.34 \%)$ it resulted from mechanical injury. A haematoma formed in the port location, then evolved into an abscess, which self-evacuated through the skin. Targeted antibiotic therapy and change of wound dressings were applied. After the infection receded, port relocation was performed, but recurrent suppurative complications led to removal of

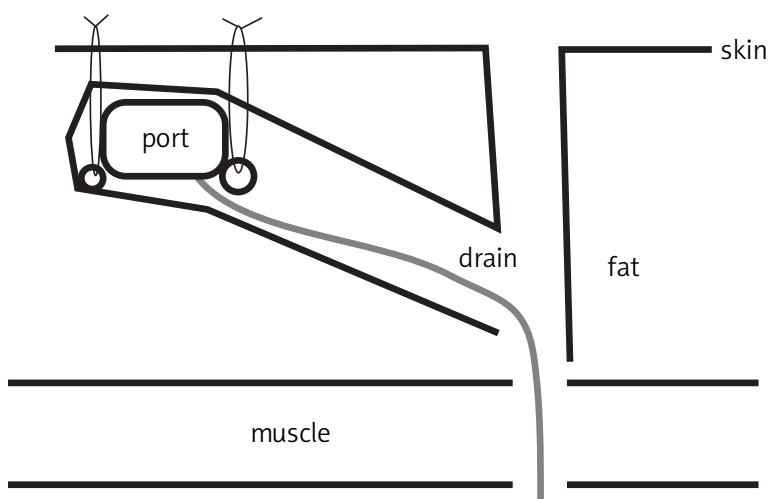

Figure 4. Port positioning - a cross-section

a band. Bacteriological examination confirmed bacterial colonization with microorganisms found earlier in the port abscess. In 3 patients (1.03) skin necrosis occurred over the port due to ischaemia from the port pressure - reduction of overweight and adipose tissue thickness led to rupture of the skin stretched over the port. It happened 11, 12 and 15 months after the surgery. Repositioning the port laterally to the trocar entry solved the problem.

No port and connecting drain leak or drain separation were found. No accidental connecting drain puncture with its damage occurred during band adjustment.

Port infection features were found in 6 patients (2.05\%) from group II and 4 patients (1.23\%) in group III. No port infection occurred in group I. In group II inflammatory infiltrate with oedema at the port site was found in 4 patients (1.37\%) in the first post-operative week at the control visit. Signs of infection

Table VI. Complications rate

\begin{tabular}{|lcccc|}
\hline Complication & Group I $(n=20)$ & Group II $(n=292)$ & Group III $(n=325)$ & Total $(n=637)$ \\
\hline $\begin{array}{l}\text { Early rotation of the port }-6 \text {-8 weeks } \\
\text { after the procedure, } n(\%)\end{array}$ & $11(55)$ & 0 & $3(0.92)$ & $14(2.19)$ \\
\hline $\begin{array}{l}\text { Late port rotation }-12 \text { months } \\
\text { after procedure, } n(\%)\end{array}$ & $2(10)$ & $3(1.03)$ & $3(0.92)$ & $8(1.26)$ \\
\hline Mechanical damages of the port, $n(\%)$ & 0 & $1(0.34)$ & 0 & $1(0,16)$ \\
\hline Skin lesions over the port, $n(\%)$ & 0 & $4(1.37)$ & 0 & $4(0.63)$ \\
\hline Port region infections, $n(\%)$ & $2(10)$ & $6(2.05)$ & $4(1.23)$ & $12(1.88)$ \\
\hline All complications, $n(\%)$ & $15(75)$ & $14(4.79)$ & $10(3.08)$ & $39(6.12)$ \\
\hline
\end{tabular}


receded after oral antibiotic. One patient $(0.34 \%)$ after a consecutive adjustment 10 months after surgery suffered from an abscess with suppurative fistula at the port site. Targeted antibiotic therapy and fistula wash with $0.25 \% \mathrm{AgNO}_{3}$ were implemented and the wound healed 4 weeks later. In another patient inflammatory infiltrate was removed laparoscopically at the patient's demand due to lack of treatment progress and non-adherence (irregular visits, noncompliance with medication regimen). In group III inflammation at the port site occurred within the first post-operative week and oral antibiotics were curative in all cases (Table IV).

Height to diameter ratio of the port was significantly lower in group III than in group I. In groups I and II (MiniMizer Extra) it was 0.82 .

\section{Discussion}

Laparoscopic adjustable gastric banding is a safe procedure, easy to perform for an experienced bariatric surgeon. Additionally, it is associated with a small number of intraoperative and early postoperative complications. However, it is alone among bariatric procedures in requiring continuous, extending to many years, patient care, and necessitates band adjustments. As Korenkov [1] said, the port is the 'Achilles' heel' of the method and deserves more attention. Indeed, in many publications port-associated complications are considered marginal and are mentioned (most likely) among 'other minor complications' [2]. Similarly, when describing the operative technique, many surgeons mention neither port localization, nor the method of port stabilization. Indeed, port complications are generally benign, though they may require band removal (for ascending infection) [3-5].

Port-related complications affect the quality of performance of personnel involved in band regulation. In a number of countries it is done by an operating surgeon; hence correct port placement and its fixation during surgery facilitate future interventions. There is no uniform consensus as to location and method of port implantation. Most often it is placed on the left costal arch, on the lower $1 / 3$ of the sternum or xiphoid or left hypochondriac region [1, 6-11]. Many surgeons stabilize the port with 3-4 interrupted sutures with periosteum of the sternum or anterior lamina of the fascia of the left rectus abdominis muscle [12-19]. To shorten the operative time and improve port stabilization, Fabry and Piorkowski first stitch the port to the net, which is then fastened to the fascia of the rectus abdominis muscle $[20,21]$. Obtech and Inamed companies facilitated port stabilization with mechanical staples. These are the Velocity (Obtech) and Rapidport (Inamed) systems. Their introduction shortened the time required for port stabilization (from 4 to $1 \mathrm{~min}$ ), and facilitated it even in patients with very thick subcutaneous adipose tissue. The authors who describe application of the Velocity system note very secure port stabilization [22-24]. Longterm results are not known yet. Some surgeons give up port stabilization while positioning it on the sternum or subcutaneously $[11,25,26]$. The port placed on the sternum, however, is easy to puncture, often causes discomfort and after weight reduction is quite visible and the skin above it can easily be damaged or ulcerated [27, 28]. Thus, many surgeons give up this technique in women. Port implantation on the fascia of the rectus abdominis muscle is believed to be technically challenging. Such a port is not easily accessible for needle puncture, and there arises the risk of accidental puncture of the connecting drain and its damage with leakage. Hence, some surgeons place the port subcutaneously, where it is easily accessible and can be palpated without any visual methods; also needle puncture is simple and safe, and does not cause connecting drain damage [21, 29-32].

Port dimensions, especially height to diameter ratio, are important for its stability. The lower the value, the lower the predilection to port rotation. However, specific construction of Huber's needle, which enforces minimal port height, must be taken into account. Thus, while trying to reduce the size of the port the manufacturers are forced to decrease its diameter. A cylinder-shaped port invented by Helioscope is an interesting choice. In our department this type of port was used in three patients. Too small number of patients and too short follow-up time do not allow us to draw conclusions.

In our department we preferred the subcutaneous port implantation technique, medially to the left working tool trocar through a previously formed canal. No port stabilization was made. When compared to the available literature data, our results were satisfactory. Port accessibility and lack of complications confirmed this strategy. A change of the band brand for HospiMedical (MiniMizer Extra) resulted in implantation of the ports attached to the 
band nearly square in section (height/diameter ratio 0.87 - close to 1 ). On the first regulation in 20 patients we found rotation greater than $90^{\circ}$ in 11 cases. This finding urged us to develop and implement the technique described above. It resulted in only minimal elongation of the procedure from 19-20 min to $24 \mathrm{~min}$ (statistically insignificant), yet the procedure of port implantation and stabilization is statistically significantly longer than the previous one. However, it allows avoidance of port rotation, and practically abolishes the possibility of connecting drain damage with a needle, which often occurs in ports located on the fascia. Nevertheless, other complications such as infections and skin ulceration occur as frequently as in other centres [33, 34]. Mechanical damage occurs infrequently and is not a significant problem.

\section{References}

1. Korenkov M, Sauerland S, Yücel N, et al. Port function after laparoscopic adjustable gastric banding for morbid obesity. Surg Endosc 2003; 17: 1068-71.

2. Suter M, Calmes JM, Paroz A, Giusti V. A 10-year experience with laparoscopic gastric banding for morbid obesity: high long-term complication and failure rates. Obes Surg 2006; 16: 829-35.

3. Angrisani L, Furbetta F, Doldi SB, et al. Lap Band ${ }^{\circledR}$ adjustable gastric banding system: the Italian experience with 1863 patients operated on 6 years. Surg Endosc 2003; 17: 409-12.

4. Szold A, Abu-Abeid S. Laparoscopic adjustable silicone gastric banding for morbid obesity: results and complications in 715 patients. Surg Endosc 2002; 16: 230-3.

5. Bobowicz M, Michalik M, Orłowski M, Frask A. Bariatric single incision laparoscopic surgery - review of initial experience. Videosurgery and Other Miniinvasive Techniques 2011; 6: 48-52.

6. Wellborn JC, Wellborn SH, Wellborn T. Technique for nonfascial fixation of the laparoscopic adjustable gastric band access port. Surg Obes Relat Dis 2010; 6: 429-33.

7. Spivak H, Gold D, Guerrero CST. Optimization of access-port placement for the Lap-Band ${ }^{\text {TM }}$ System. Obes Surg 2003; 13: 909-2.

8. Chapman AE, Kiroff G, Game P, et al. Laparoscopic adjustable gastric banding in the treatment of obesity: a systematic literature review. Surgery 2004; 135: 326-51.

9. Nowara HA. Egyptian experience in laparoscopic adjustable gastric banding (technique, complications and intermediate results). Obes Surg 2001; 11: 70-5.

10. O'Brien PE, Dixon JB, Brown W, et al. The laparoscopic adjustable gastric band (Lap-Band $\left.{ }^{\circledR}\right)$ : a prospective study of medium-term effects on weight, health and quality of life. Obes Surg 2002; 12 : 652-60.

11. Mizrahi S, Avinoah E. Technical tips for laparoscopic gastric banding: 6 years' experience in 2800 procedures by a single surgical team. Am J Surg 2007; 193: 160-5.

12. Sauerland S, Angrisani L, Belachew M, et al. Obesity surgery evidence-based guidelines of the European Association for Endoscopic Surgery (EAES). Surg Endosc 2005; 19: 200-21.
13. Korenkov M, Kneist W, Heintz A, Junginger T. Technical alternatives in laparoscopic placement of an adjustable gastric band: experience of two German university hospitals. Obes Surg 2004; 14: 806-10.

14. Speybrouck S, Aelvoet C, Tollens T, Vanrykel JP. Use of gentamicin in the treatment of access-port infections. Obes Surg 2005; 15: 1278-81.

15. Launay-Savary MV, Slim K, Brugère C, et al. Band and port-related morbidity after bariatric surgery: an underestimated problem. Obes Surg 2008; 18: 1406-10.

16. Lattuada E, Zappa MA, Mozzi E, et al. Injection port and connecting tube complications after laparoscopic adjustable gastric banding. Obes Surg 2010; 20: 410-4.

17. Weiss H, Nehoda H, Labeck B, et al. Injection port complications after gastric banding: incidence, management and prevention. Obes Surg 2000; 10: 259-62.

18. Hady RH, Iwacewicz P, Dadan J. Evaluation of the efficiency of chosen methods of surgical treatment of pathological obesity in our own material. Videsurgery and Other Miniinvasive Techniques 2008; 3: 39-44.

19. Stanowski E, Paśnik K. Bariatric surgery - the current state of knowledge. Videsurgery and Other Miniinvasive Techniques 2008; 3: 71-86.

20. Piorkowski JR, Ellner SJ, Mavanur AA, Barba CA. Preventing port site inversion in laparoscopic adjustable gastric banding. Surg Obes Relat Dis 2007; 3: 159-61.

21. Fabry H, Van Hee R, Hendrickx L, Totte E. A technique for prevention of port complications after laparoscopic adjustable silicone gastric banding. Obes Surg 2002; 12: 285-8.

22. Miller KA. Evolution of gastric band implantation and port fixation techniques. Surg Obes Relat Dis 2008; 4 (3 Suppl): S22-30.

23. Türler A, Standop J, Schäfer N, et al. Port stapling for simplified port implantation in laparoscopic adjustable gastric banding. Chirurg 2007; 78: 828-32.

24. Fried M, Kormanova K, Kasalicky M. Comparison of SAGB QC "Classic" Titanium Port and Velocity ${ }^{\mathrm{TM}}$ Port: pilot phase prospective randomized study on perioperative and short-term postoperative implantation outcomes. Obes Surg 2006; 16: 716-20.

25. Miller K, Pump A. Mechanical versus suture fixation of the port in adjustable gastric banding procedures: a prospective randomized blinded study. Surg Endosc 2008; 22: 2478-84.

26. Arvind N, Bates SE, Morgan JD, et al. Fixation of the access-port is not required in gastric banding. Obes Surg 2007; 17: 577-80.

27. Susmallian S, Ezri T, Elis M, Charuzi I. Access-port complications after laparoscopic gastric banding. Obes Surg 2003; 13: 128-31.

28. Steffen R, Biertho L, Ricklin T, et al. Laparoscopic Swedish adjustable gastric banding: a five-year prospective study. Obes Surg 2003; 13: 404-11.

29. Keidar A, Carmon E, Szold A, et al. Port complications following laparoscopic adjustable gastric banding for morbid obesity. Obes Surg 2005; 15: 361-5.

30. Eid GM, Gourash W, Collins JL. A novel technique for fascial fixation of laparoscopic adjustable gastric band ports. Surg Endosc 2006; 20: 697-9.

31. Szewczyk T, Modzelewski B. Perioperative Comparison of the MiniMizer ${ }^{\circledR}$ Extra Band with the other laparoscopic gastric bands. Obes Surg 2006; 16: 646-50. 
32. Orłowski M, Szydłowski K, Frask A, et al. Complications after surgical treatment of obesity based on own material. Videosurgery and Other Miniinvasive Techniques 2008; 3: 45-52.

33. Fried M, Miller K, Kormanova K. Literature review of comparative studies of complications with Swedish band and Lap-Band ${ }^{\circledR}$. Obes Surg 2004; 14: 256-60.

34. Chevallier JM, Zinzindohoué F, Douard R, et al. Complications after laparoscopic adjustable gastric banding for morbid obesity: experience with 1,000 patients over 7 years. Obes Surg 2004; 14: 407-14. 